\title{
Landscape Changes and Their Socio-Economic Driving Factors in Coastal Zone
}

\author{
Lili Zhao ${ }^{1}$, Xuncheng Fan ${ }^{1 *}$, Dongjin $\mathrm{He}^{2}$ \\ ${ }^{1}$ College of Urban and Rural Construction, Shaoyang University, Shaoyang, 422000 China \\ ${ }^{2}$ Forestry College, Fujian Agriculture and Forestry University, Fuzhou, 350002 China
}

Received: 4 December 2020

Accepted: 11 February 2021

\begin{abstract}
The coastal zone is not only the most active natural area on the Earth's surface but also the area with the most superior resources and environmental conditions. The sustainable development of the coastal ecological environment is closely related to the survival and development of human beings. In recent centuries, the coastal landscape has undergone tremendous changes with a massive increase in human population in the coastal areas. Therefore, it is urgent to identify the specific driving factors that affect coastal landscape changes to achieve sustainable management of coastal landscapes. In this paper, the Ningde Coastal Zone in China is selected as a case study. The study focuses on the impact of socio-economic and policy factors on coastal landscape changes and identifies the differences in the impact of various socio-economic factors on coastal landscape changes based on remote sensing data and statistical data. The results show that population, economy, consumption, and technology are the main driving factors affecting coastal landscape changes. The ranking of the impact of these factors on the coastal zone follows the order population>economy>consumption>technology. The influence of these driving factors on coastal landscapes continues to increase. In addition to socio-economic driving factors, policies are also one of the driving factors affecting coastal landscape changes.
\end{abstract}

Keywords: land use, principal component analysis, Fujian Province, Ningde City

\section{Introduction}

The coastal zone experiences the strongest interactions between land and sea and is also considered the most important ecological interlock zone in the world. "Agenda 21" adopted by the United Nations in 1992 states that more than $50 \%$ of the global population resides within $60 \mathrm{~km}$ of coastline [1]; in 2020, this proportion increased to $75 \%$. It is estimated that by

*e-mail: xunchengfan@126.com
$2030,50 \%$ of the global population will live in areas $100 \mathrm{~km}$ from the coast [2]. China has a coastline of $18,000 \mathrm{~km}$ and an island coastline of $14,000 \mathrm{~km}$, where $60 \%$ of the population is concentrated within $60 \mathrm{~km}$ of the coastline [3]. Although coastal areas only account for $13 \%$ of the total land area in China, more than $50 \%$ of its large cities, $40 \%$ of the small and mediumsized cities, and more than $40 \%$ of the population is concentrated in coastal zones. These zones also contribute to approximately $70 \%$ of the gross domestic product in China [4-5].

Coastal ecosystems provide a variety of services. They do not only provide food, and habitats and 
nurseries for $80 \%$ to $90 \%$ of the marine fish and shellfish worldwide; they also regulate water quality, alleviate climate change, and reduce sea level rise and geological disasters [2]. The study of coastal ecosystems can be vital to social and economic development because coastal zones host abundant resources and can provide ecosystem services. However, the rapid increase in coastal populations in recent centuries has seriously reduced the resilience of coastal ecosystems and affected their normal output of ecosystem services. More seriously, recent human activity driven by highspeed global urbanization has increasingly damaged coastal zones [6]. These zones face severe environmental problems, including water, oil, and solid waste pollution; destruction of biological habitats; invasion of alien species; loss of biodiversity; reduction of fisheries; sea level rise; coastal erosion; seawater intrusion; and land salinization from global warming [7-10]. Therefore, the ecological security and sustainable development of coastal areas are under significant threat, which means that research on the sustainable development of coastal zones is high priority in coastal planning and landscape sustainability.

A landscape pattern is a combination of landscapes of different shapes and sizes embedded in the land surface; it is the product of interactions between humans and nature [11]. Landscape changes refer to the changes in the spatial structure and function of landscape over time [12]. The changes in landscape patterns have become an important indicator of the relationship between human society and natural ecosystems [13, 14]. In coastal zones, the landscape pattern is undergoing increasing levels of disturbance and becoming highly fragmented. Landscape changes are becoming more complex with the ongoing development of human society, and hence, the ecological issues of coastal zones are becoming increasingly prominent. In this context, there is a critical need for research on the changes in coastal landscape patterns and the underpinning driving mechanisms. This research contributes to the sustainable development of coastal zones and the alleviation of pressure on natural ecosystems as a result of the changes in coastal landscape patterns [15-16].

Research on the dynamic changes in coastal landscape patterns and the mechanisms driving these has been conducted in many countries to date. Parcerisas et al. [17] used landscape indicators to study the changes in the landscape pattern of the Spanish Mediterranean coast from 1850 to 2005 and the socioeconomic forces driving this. Their results showed that the environment in the study area deteriorated rapidly over the past 150 years, with urban expansion and agricultural abandonment being the main causes of landscape degradation. Rivis et al. [18] analyzed the trends in land cover and landscape development in the coastal zone of Estonia under the effect of both social and natural factors and revealed that the diversity of seabed landforms a key factor affecting the speed and magnitude of landscape changes. Most changes to the coastal landscape caused by natural processes occurred near the coastline, while the impact of human activity on the coastal landscape increased with distance therefrom. Petrisor et al. [2] studied the evolution of the landscape in coastal areas of Vietnam and Algeria and found that urban expansion and the rapid development of tourism were the main reasons for changes in the landscape along the coast of Vietnam while urbanization and agricultural development were the main causes of landscape degradation along the coast of Algeria, and explosive growths in population, the migration of rural populations, and urban dwellers have exacerbated the degradation of the landscape in the coast of Algeria. Ou et al. [19] studied the characteristics of changes in the landscape pattern and the mechanisms driving these in the coastal zone of Yancheng, northern Jiangsu, China. Their results showed that economic development and population growth have led to the transformation of natural coastal landscape patterns into artificial landscape patterns, reductions in the heterogeneity of natural landscapes, and increases in the heterogeneity of artificial landscapes. Ding [20] used using the landscape index method to analyze the process by which landscape in the Bohai Rim region evolved from 1980 to 2010 and noted that agriculture, fisheries, and human economic activities were the driving forces behind the changes in the pattern of that landscape. Xu et al. [21] interpreted three-phase remote sensing images and combined this field investigations, sampling analysis, the landscape pattern index method, and a transfer matrix to study the spatiotemporal dynamics of the landscape pattern of the Rizhao coastal zone in China. Their results showed that the evolution of regional landscape patterns was closely related to changes in natural conditions and human activities.

The mechanisms that drive the evolution of coastal landscape patterns include both natural and human factors. However, the former are relatively stable over a short time scale; therefore, at this scale, human activities are the main factors driving changes in coastal landscape patterns [22]. Different scholars have different understandings of the latter. Ehrich and Daily [23] state that the human factor should include population, wealth, and technology while Turner et al. [22] state that it should include population, income, technology, policy, economy, and culture. The International Human Dimensions Programme on Global Environmental Change (IHDP) divides the socio-economic factors that affect terrestrial landscape changes into direct and indirect factors. Indirect factors include population change, technological developments, economic growth, political and economic policies, and wealth and value orientation. Of these six factors, the impact of population on changes in terrestrial landscape patterns has always been an important part of research on the mechanisms driving the former. Therefore, this study assumed that population was one of the main factors driving the evolution of the coastal landscape pattern of the Ningde coastal zone. 
China underwent tremendous social, economic, and cultural changes at the beginning of the $21^{\text {st }}$ century and these changes were reflected clearly in changes to the terrestrial landscape. Since 2010, the Fujian Provincial Government has enacted a series of strategic arrangements to develop the economy of coastal areas and accelerate the development of the marine economy. The development and utilization of land in the coastal area of Ningde has led to an unprecedented climax. Ningde is not just the coastal city with the longest coastline in Fujian Province; it is also home to two national forest parks, a global geological park, and a national wetland park. Therefore, changes in the landscape pattern of Ningde will inevitably have a profound impact on local biodiversity and ecology. Owing to its unique characteristics, the Ningde coastal zone has always been a key site for various studies. It has attracted a lot of attention from scholars and experts, and it was the focus of a series of studies [2427]; however, these focus mainly on the vulnerability of the models used to evaluate of erosion, town planning and resource development, aquaculture water quality status, and the ecological risk from invasive plants in coastal wetlands. There have been no studies on the evolution of landscape patterns in the Ningde coastal zone, and there has been no work on quantitative identification of the contribution of factors driving coastal landscape change. Therefore, this study uses the evolution of coastal landscape patterns in Ningde as the research object and seeks to quantify the changes in landscape and the associated drivers using landscape indices, and principal component analysis (PCA) to analyze and summarize the characteristics of changes in the landscape pattern in coastal areas and the driving mechanism behind this under the background of rapid economic development. This study both identified the driving factors affecting the Ningde coastal zone and ranked them according to their influence on the changes in the landscape. The outcomes from this study are of important practical significance and provide a reference for the accurate prediction of changes to coastal landscape patterns, the appropriate planning of coastal lands, and the sustainable development of the coastal zone.

\section{Material and Methods}

\section{Selection and Overview of Study Area}

The Ningde coastal zone is located northeast of Fujian Province (Fig. 1). The coastline is $878.16 \mathrm{~km}$ in length, accounting for one third of the Fujian Province coastline. The area of sea is $44,500 \mathrm{~km}^{2}$, constituting one third of the total area of sea for Fujian Province. It provides the largest breeding grounds for the large yellow croaker and is the only harbor providing around the clock berthing for half a million ton ships in China [28].

The total population in the coastal zone increased from 2.08 million to 2.35 million from 2000 to 2019, respectively; this represents an increase of 0.27 million. By the end of 2019, residents in the coastal zone accounted for $66 \%$ of residents in Ningde. The population density increased from 332 people $/ \mathrm{km}^{2}$ in 2000 to 375 people $/ \mathrm{km}^{2}$ in 2019 [29]. The coastal zone has four administrative districts; Fuding, Fu'an, Xiapu, and Jiaocheng. Fuding has the highest population density at 392 people $/ \mathrm{km}^{2}$, while Xiapu has the lowest population density at 322 people $/ \mathrm{km}^{2}$ [29-32]. The zone experiences a typical mid-subtropical monsoon climate as it is located in the mid and low latitudes and is affected by solar radiation, mountain topography, and monsoons. The average annual temperature is between 18.5 and $19.3^{\circ} \mathrm{C}$, and the extreme maximum temperature is $43.2^{\circ} \mathrm{C}$, whereas the extreme minimum temperature is

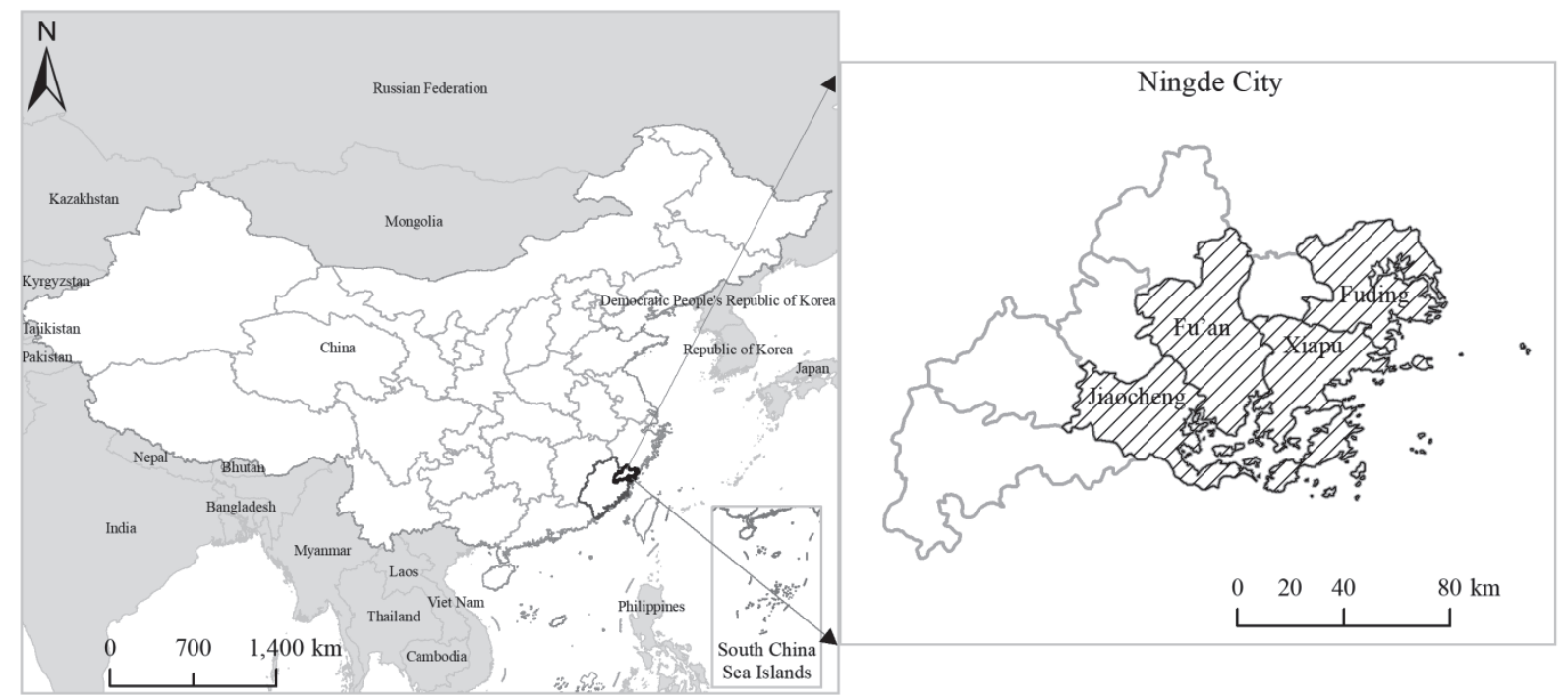

Fig. 1. Map of study area. 
between 0 and $3.9^{\circ} \mathrm{C}$.

Based on landform type and soil combination characteristics, land resources may be divided into three categories: mountain soil, plain agricultural soil, and tidal flats. Mountain and hilly areas account for $73.3 \%$ of the entire coastal zone, followed by tidal flats. The cities of Fu'an, Xiapu, Fuding, and Jiaocheng are $1810,1708,1542$, and $1505 \mathrm{~km}^{2}$, respectively [29-32]. A large amount of freshwater flows into the Ningde coastal zone, introducing large quantities of organic matter and inorganic salt into the sea. The annual average temperature of the sea is between 11 and $29^{\circ} \mathrm{C}$, and salinity is between 26 and $29 \%$.

\section{Remote Sensing Data}

The remote sensing data, including Landsat-5 Thematic Mapper (TM) (2000 and 2009) and the Landsat-8 Operational Land Imager (OLI) (2014), were obtained from the Geospatial Data Cloud (http://www. gscloud.cn/). The cloud coverage of this imagery was less than $10 \%$. Four scenes were required to cover the entire study area; their track numbers were 119/42, $119 / 41,118 / 41$, and 118/42. Data on the socio-economic drivers of Ningde City from 2000 to 2014 were obtained from the statistical yearbook of the Ningde Municipal Statistical Bureau [30-32], and the administrative zoning maps were obtained by the Geographical Information Monitoring Cloud Platform (http://www.dsac.cn/).

These remote sensing imageries were level 1T data. These data were subjected to digital elevation model terrain and the correction of ground control point geometry prior to downloading. Color synthesis, mosaic, clip, and object-oriented classification were constructed using the Environment for Visualizing Images (ENVI) 5.2 tool. The selected land-use types were unused land, dry land, paddy fields, rivers, forest and grassland (combined), construction land, lakes, aquaculture, and reservoirs. The remote sensing imagery from the Landsat-5 TM and Landsat-8 OLI were processed using 4, 3, 2 bands and 5, 4, 3 bands for color synthesis, respectively. In total, 250 samples for each land-use type were selected to obtain better classification results. Interactive verification using Google Earth and field investigations were carried out. The final classification accuracy of the remote sensing images of 2000, 2009 and 2014 was $89.30 \%$, 94.50\%, and $92.50 \%$ respectively, meeting the requirements of this study.

\section{Landscape Indices}

The following section describes the selected landscape indices, which clearly express landscape changes in the study area [33-34]:

(1) Total landscape Area (TA): This is the total area of a study region. This index determines the scope of the landscape and the largest scale of research and is the basis for calculating other indicators. In the design of nature reserves, the landscape area is one of the most important indicators to protect dominant, rare, and endangered species. It is expressed as follows:

$$
T A=A
$$

...where $T A$ is the total area of the study area (ha), and the value is always greater than 0 .

(2) Patch richness (PR): This is the number of patch types. PR has an impact on many ecological processes and is one of the key indicators representing landscape composition and spatial heterogeneity. There is a strong positive correlation between PR and species richness. It is particularly important for organisms requiring multiple habitat conditions. PR is expressed as follows:

$$
P R=m
$$

...where $P R$ is the richness of the landscape patch, which is greater than or equal to 1 ; and $m$ is the total number of patch types.

(30) Fractal dimension of the perimeter area (PAFRAC): This index represents the complexity of patch shape, which may be expressed as follows:

PAFRAC $=\frac{\frac{2}{\left[N \sum_{i=1}^{m} \sum_{j=1}^{n}\left(\ln p_{i j} \ln a_{i j}\right)\right]-\left[\left(\sum_{i=1}^{m} \sum_{j=1}^{n} \ln p_{i j}\right)\left(\sum_{i=1}^{m} \sum_{j=1}^{n} \ln a_{i j}\right)\right]}}{\left[N \sum_{i=1}^{m} \sum_{j=1}^{n} \ln \left(p_{i j}\right)^{2}\right]-\left[\sum_{i=1}^{m} \sum_{j=1}^{n} \ln p_{i j}\right]^{2}}$

...where PAFRAC is the fractal dimension of the perimeter area; $a_{i j}$ is the area of patch, $i j ; p_{i j}$ is the perimeter; and $N$ is the total number of patches. The PAFRAC is between 1 and 2. When the PAFRAC is close to 1 , this signifies a simpler patch shape, whereas a value close to 2 indicates that the shape is more complex.

(4) Number of patches (NP): This refers the total number of patches of a specific landscape type. It is positively correlated with the fragmentation of a landscape type. NP has an impact on many ecological processes including the determination of the spatial distribution of various species and their secondary species in a landscape and changes in the stability of interactions among species. Moreover, NP has an important influence on the spread of various disturbances in a landscape. NP may be expressed as follows:

$$
\begin{aligned}
& N P_{1}=n \\
& N P_{2}=n_{i}
\end{aligned}
$$

...where $N P_{1}$ and $n$ are the number of patches at the landscape level and the total number of each patch type, respectively; $N P_{2}$ and $n_{i}$ are the number of patches at the level of patch types and the number of patches of patch type, $i$, respectively. The NP is greater than or equal 
to 1 ; an NP of 1 , signifies that there is only one patch in the entire landscape.

(5) Patch density (PD): This signifies the number of patches per unit area in a landscape. This reflects the fragmentation of entire landscape patches and may be described as follows:

$$
P D=\frac{n}{A} \times 100
$$

...where $P D$ is expressed in $\mathrm{n} / 100$ ha and is greater than $0 ; n$ is the total number of specific patches in a landscape; and $A$ is the total area of the study region.

(6) Largest patch index (LPI): This is the proportion of the largest patch area to the entire landscape area. This index determines the dominant type of landscape, and its value reflects the abundance of dominant and other species. The changes in the LPI are indicative of the change in the intensity and frequency of interference. The LPI may be expressed as follows:

$$
L P I=\frac{\max _{j=1}^{n}\left(a_{i j}\right)}{A} \times 100
$$

...where $L P I$ is expressed in \%, ranging between 0 and 100 ; and $a_{i j}$ is the area of patch, $i j ; A$ is the total area of the study region.

(7) Shannon's diversity index (SHDI): This index represents the richness and complexity of landscape types. The SHDI range is greater than or equal to 0 . When the SHDI is equal to 0 , it indicates that there is only one type of patch in a landscape. Thus, an increase in the SHDI signifies an increase in the number of patch types, reflecting the heterogeneity of the landscape. It is particularly sensitive to the uneven distribution of patch types in a landscape. The SHDI may be expressed as follows:

$$
S H D I=-\sum_{i=1}^{m}\left[P_{i} \ln P_{i}\right]
$$

...where $P_{i}$ is the existence probability of patch type, $i$, in a landscape; and $m$ is the total number of patch types.

(8) Patch cohesion index (COHESION): This refers to the natural connectivity of patch types. In a closed area, a higher COHESION indicates better connectivity and lower landscape fragmentation. COHESION may be expressed as follows:

$$
\text { COHESION }=\left[1-\frac{\sum_{j=2}^{n} p_{i j}}{\sum_{j=2}^{n} p_{i j} \sqrt{a_{i j}}}\right]\left[1-\frac{1}{\sqrt{A}}\right]^{-1}
$$

...where COHESION ranges between $0 \%$ and $100 \%$; $a$ is the area of patch, $i j$; and $P$ is the circumference.

(9) Contagion index (CONTAG): This indicates the agglomeration of different patch types in a landscape. As this index contains spatial information, it is one of the most important indices to describe landscape patterns, which is expressed as follows:

CONTAG $=\left[1+\frac{\sum_{i=1}^{m} \sum_{k=1}^{m}\left(P_{i} \frac{g_{i k}}{\sum_{k=1}^{m} g_{i k}}\right) \ln \left(P \frac{g_{i k}}{\sum_{k=1}^{m} g_{i k}}\right)}{2 \ln m}\right] \times 100$

...where CONTAG is the aggregation index (\%), ranging between $0 \%$ and $100 \% ; P_{i}$ is the ratio of patch type, $I$, to the total landscape area; and $g_{i k}$ is the number of adjacent grid cells among patch types. A greater CONTAG indicates that a certain dominant patch type in a landscape has better connectivity, whereas a lower CONTAG indicates higher fragmentation of patches.

(10) Percentage of landscape (PLAND): This is the proportion of a specific landscape type in the entire study area. It may be used to determine the dominant patches, biodiversity, and dominant species in a landscape, which is expressed as follows:

$$
P L A N D=p_{i}=\frac{\sum_{i=1}^{n} a_{i j}}{A} \times 100
$$

...where PLAND ranges between $0 \%$ to $100 \%$; $a_{i j}$ is the area of patch, $i j$; and $p_{i}$ is the proportion of patch type, $I$, in the entire landscape.

(11) Interspersion juxtaposition index (IJI): This reflects the distribution of various patch types. It is one of the most important indicators to describe the spatial pattern of landscapes. It is a significant indicator of the distribution characteristics of ecosystems severely restricted by certain natural conditions. For example, various ecosystems in mountainous areas have a circular distribution due to the vertical zonality, generating a low IJI. In contrast, many transitional vegetation types in arid areas are affected by the distribution of water, generating a high $I J I$. The $I J I$ may be expressed as follows:

$$
\begin{gathered}
I J I=-\frac{\sum_{i=1}^{m} \sum_{k=i+1}^{m}\left[\left(\frac{E_{i k}}{\sum_{k=1}^{m} E_{i k}}\right) \ln \left(\frac{E_{i k}}{\sum_{k=1}^{m} E_{i k}}\right)\right]}{\ln \frac{1}{2} m(m-1)} \times 100 \\
I J I_{i}=-\frac{\sum_{k=1}^{m}\left[\left(\frac{E_{i k}}{\sum_{k=1}^{m} E_{i k}}\right) \ln \left(\frac{E_{i k}}{\sum_{k=1}^{m} E_{i k}}\right)\right]}{\ln (m-1)} \times 100
\end{gathered}
$$

...where $E_{i k}$ is the side length of patch type, $I$, adjacent to various patch types; $I J I_{i}$ represents the $I J I$ of patch type, $i$. The $I J I$ ranges from $0 \%$ to $100 \%$; when it is close to $0 \%$, this indicates that a specific type is distinct from other types, whereas an $I J I$ close to $100 \%$ indicates the presence of more patches of a specific type that are adjacent to other types. 


\section{Principal Component Analysis}

PCA is a multivariate statistical method that examines the correlation between multiple variables [3537]. It is a multivariate statistical method to extract a subset of variables from the original suite of variables to express additional information using the least variables [38]. PCA was used to understand the influence of socio-economic drivers on landscape changes. Natural drivers of change were not examined as the relatively short period (14 years) of this study was considered insufficient to clearly detect the influence of such drivers on landscape changes. In contrast, socio-economic drivers have a significant impact on landscape changes in the short-term [39-40]. The Ningde coastal zone is located in the middle of the Yangtze River Delta, Pearl River Delta, and Taiwan. The socio-economic drivers relating to the economy, population, and urbanization have had a greater impact on landscape changes.

The suitability of utilizing the PCA was assessed in four systematic steps. First, the statistical yearbook was reviewed to determine the socio-economic drivers that can be quantified and are clearly connected to landscape. Second, data from these selected drivers were intact for the years 2000, 2009, and 2014. Third, data was processed in a non-dimensional manner using Statistical Product and Service Solutions (SPSS) due to the different units of each driver. Finally, Bartlett and the Kaiser-Meyer-Olkin (KMO) test were used to determine the suitability of these drivers for PCA, and then, the principal components were obtained using SPSS.

After the implementation of these PCA screening steps, a total of 18 drivers were identified. These drivers were categorized into specific types including population, economy, technology, consumption, and social awareness (Table 1). Normalized data were processed using the Bartlett and KMO test, and the significance (correlation probability) from the Bartlett test was 0.000 ; this was less than the significance level of 0.05 . The KMO was 0.825 , indicating that there was a linear correlation among these drivers; consequently, it was deemed suitable to process these factors using PCA.

\section{Results and Discussion}

\section{Landscape Changes in the Ningde Coastal Zone on Landscape Level}

Landscape indices (i.e., $T A, P R, P A F R A C, N P, P D$, LPI, SHDI, COHESION, and CONTAG) were used to quantify the landscape changes of the entire study area. Table 2 shows that during the study period, the $T A$ increased from 6102 to 6253 ha, exhibiting an increasing trend in landscape area. The $P R$ stayed the same over this time, indicating that the patch types of

Table 1. Code, name, unit, and types of the selected socio-economic drivers.

\begin{tabular}{|c|c|c|c|}
\hline Code & Name & Unit & Types of drivers \\
\hline $\mathrm{X}_{1}$ & Household registration & Household & \multirow{5}{*}{ Population } \\
\hline $\mathrm{X}_{2}$ & Total population & People & \\
\hline $\mathrm{X}_{3}$ & Urban population & People & \\
\hline $\mathrm{X}_{4}$ & Population density & People/km² & \\
\hline $\mathrm{X}_{5}$ & Rural population & People & \\
\hline$X_{6}$ & Gross domestic product & Billion USD & \multirow{8}{*}{ Economy } \\
\hline $\mathrm{X}_{7}$ & Primary industry & Billion USD & \\
\hline $\mathrm{X}_{8}$ & Secondary industry & Billion USD & \\
\hline $\mathrm{X}_{9}$ & Tertiary Industry & Billion USD & \\
\hline $\mathrm{X}_{10}$ & Industrial output & Billion USD & \\
\hline $\mathrm{X}_{11}$ & Gross agricultural output value & Billion USD & \\
\hline$X_{12}$ & Local fiscal revenue & Billion USD & \\
\hline $\mathrm{X}_{13}$ & Local fiscal expenditure & Billion USD & \\
\hline$X_{14}$ & Total investment in fixed assets & Billion USD & Technology \\
\hline $\mathrm{X}_{15}$ & Total retail sales of social consumer goods & Billion USD & \multirow{3}{*}{ Consumption } \\
\hline $\mathrm{X}_{16}$ & Urban and rural residents' savings balance & Billion USD & \\
\hline$X_{17}$ & Average annual salary of all employees & USD & \\
\hline $\mathrm{X}_{18}$ & Natural population growth rate & $\%$ & Social awareness \\
\hline
\end{tabular}


Table 2. Changes in the landscape indices of the Ningde coastal zone.

\begin{tabular}{|c|c|c|c|}
\hline Landscape indices (unit) & 2000 & 2009 & 2014 \\
\hline$T A(h a)$ & 6102 & 6115 & 6253 \\
\hline$P R(N / A)$ & 9 & 9 & 9 \\
\hline$P A F R A C(N / A)$ & 1.346 & 1.355 & 1.362 \\
\hline NP (N/A) & 13790 & 14064 & 13381 \\
\hline$P D(n / 100$ ha $)$ & 2.264 & 2.304 & 2.149 \\
\hline LPI (\%) & 63.76 & 47.30 & 46.87 \\
\hline SHDI (N/A) & 1.171 & 1.151 & 1.142 \\
\hline COHESION (\%) & 99.52 & 99.60 & 99.64 \\
\hline CONTAG (\%) & 70.97 & 71.50 & 71.57 \\
\hline
\end{tabular}

the landscape did not change. The PAFRAC increased from 1.346 in 2000 to 1.362 in 2014 , indicating that patch shapes had a tendency toward greater complexity. The NP rose from 13790 in 2000 to 14064 in 2009, and then dropped to 13381 in 2014, indicating that landscape fragmentation had initially increased and then decreased. $P D$ increased from 2.264 in 2000 to 2.304 in 2009, and then declined to 2.149 in 2014, indicating that the trajectory in the number of patches per unit area had changed from increasing to decreasing. This was because prior to 2009 , the massive increase in population and the lack of coordination of economy and environment had caused chaos in the coastal zone, where fragmentation and the density of landscape patches had rapidly increased. After 2009, urbanization had advanced significantly with continuous economic development. Therefore, the landscape showed an increase in the aggregation of coastal patches and a decrease in NP, PD, and landscape fragmentation.

The $L P I$ had reduced from $63.76 \%$ in 2000 to $46.87 \%$ in 2014, indicating that the advantage of dominant patches has gradually weakened. SHDI decreased from 1.171 in 2000 to 1.142 in 2014 , signifying a decrease in the types of patches and landscape heterogeneity of over time. COHESION had risen from $99.52 \%$ in 2000 to $99.64 \%$, indicating that the natural connectivity in the landscape had gradually increased, whereas fragmentation had decreased. CONTAG had increased from $70.97 \%$ in 2000 to $71.57 \%$ in 2014 , indicating that the landscape patches were gradually aggregating.

\section{Landscape Changes in Cities within the Ningde Coastal Zone on a Landscape Level}

The landscape indices (NP, PD, CONTAG, PAFRAC, and $S H D I$ ) were used to investigate the landscape changes in the cities. Fig. 2a) shows that during the study period, the NP of Xiapu increased from 3095 in 2000 to 4354 in 2014; this meant that the number of patches had continued to rise, indicating that landscape heterogeneity and fragmentation of Xiapu had increased. This ultimately means that the landscape of Xiapu has been greatly affected by external disturbances. The NP of Fu'an and Fuding decreased from 4300 and 3742 in 2000 to 3318 and 2824 in 2014, respectively. This shows that their landscape heterogeneity and fragmentation had decreased. The NP of Jiaocheng had only increased by 231 in 14 years, indicating that its landscape heterogeneity and fragmentation had not changed substantially.

Fig. 2b) shows that the number of patches per unit area of Xiapu continued to increase from 1.677 in 2000 to 2.384 in 2014. In contrast, PD of Fu'an and Fuding continued to decline; Fu'an had the largest decrease in PD of 0.596 , whereas there was only marginal change in the $P D$ of Jiaocheng.

Fig. 2c) shows that the average CONTAG in Fuding over the past 14 years was $76.81 \%$; this was significantly higher than that of other cities. This indicates that Fuding had the lowest level of landscape fragmentation. The average CONTAG in Fu'an was only $65.92 \%$, which was significantly lower than that of other cities. Therefore, Fu'an experienced the highest level of landscape fragmentation. However, the CONTAG for Fu'an continued to rise from $64.47 \%$ in 2000 to $67.49 \%$ in 2014. This indicates that landscape fragmentation in Fu'an had gradually decreased. The CONTAG of Jiaocheng and Xiapu showed a downward trend, indicating that landscape fragmentation in these cities had gradually increased.

Fig. 2d) illustrates that the PAFRAC for these cities showed an upward trend, indicating that the patch shape of the Ningde coastal zone was increasing in complexity from 2000 to 2014. The PAFRAC of Jiaocheng experienced the greatest increase from 1.345 in 2000 to 1.377 in 2014. The PAFRAC for Xiapu had initially risen from 1.326 in 2000 to 1.354 in 2009 , and then declined to 1.341 in 2014 . This indicates that patch shape in Xiapu was initially complex and then became simple. There was little change in patch shape for Fu'an and Fuding; however, the average PAFRAC in Fu'an was 1.370 . This is the highest value, indicating that the patch shape of Fu'an was the most complex.

Fig. 2e) shows that Fu'an had the largest average SHDI of 1.361, indicating that its patch composition was the most complex. In contrast, the average SHDI of Fuding was the smallest, at only 0.945 , indicating that the patch composition of Fuding was the simplest. However, both the SHDI values in these cities was decreasing. The SHDI of Jiaocheng and Xiapu showed a slight upward trend, indicating a more diversified patch composition; however, their values had not changed considerably.

\section{Landscape Changes in the Ningde Coastal Zone in Terms of Patch Types}

Landscape indices (PLAND, NP, IJI, and PAFRAC) were used to quantify landscape changes in terms of 

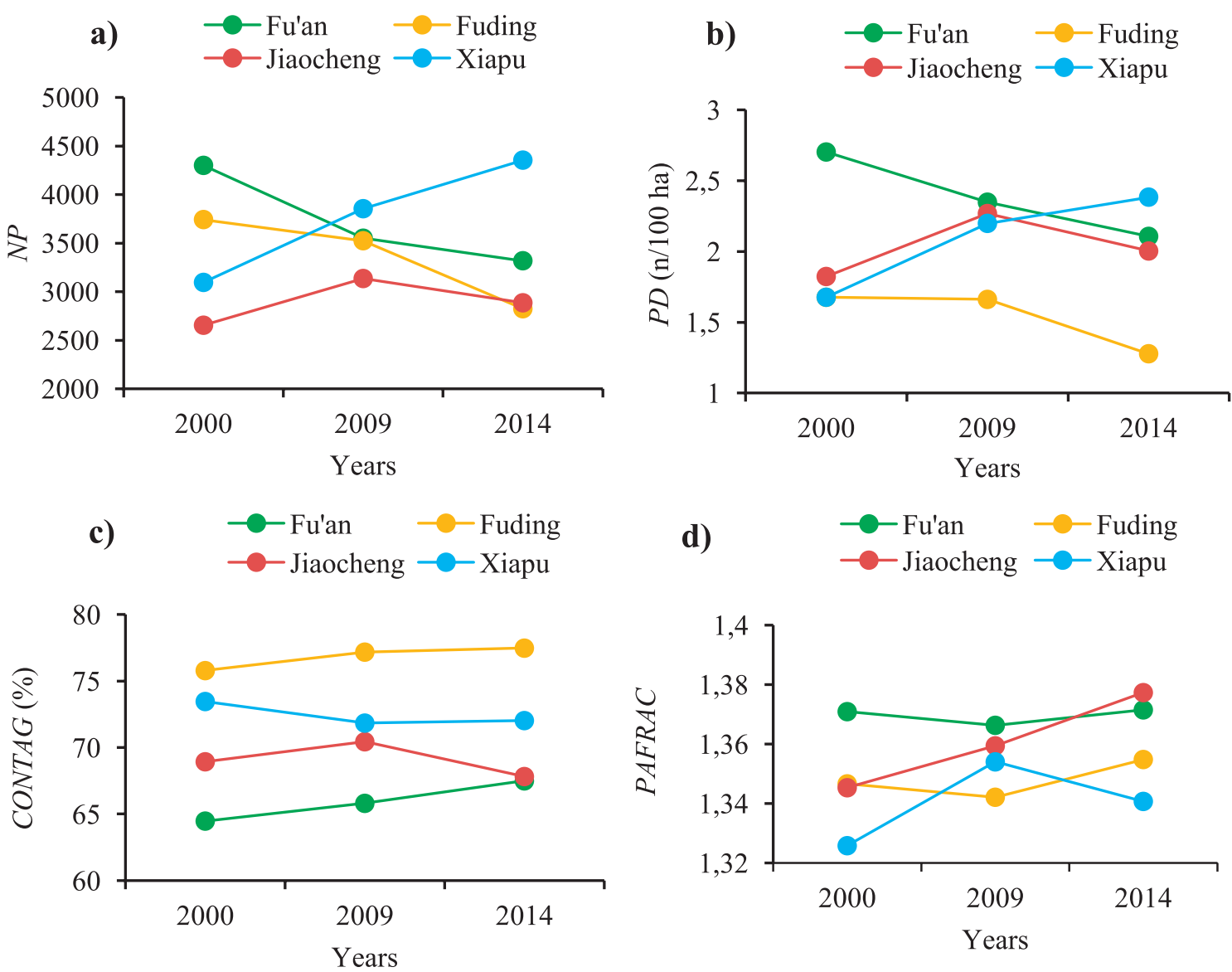

d)
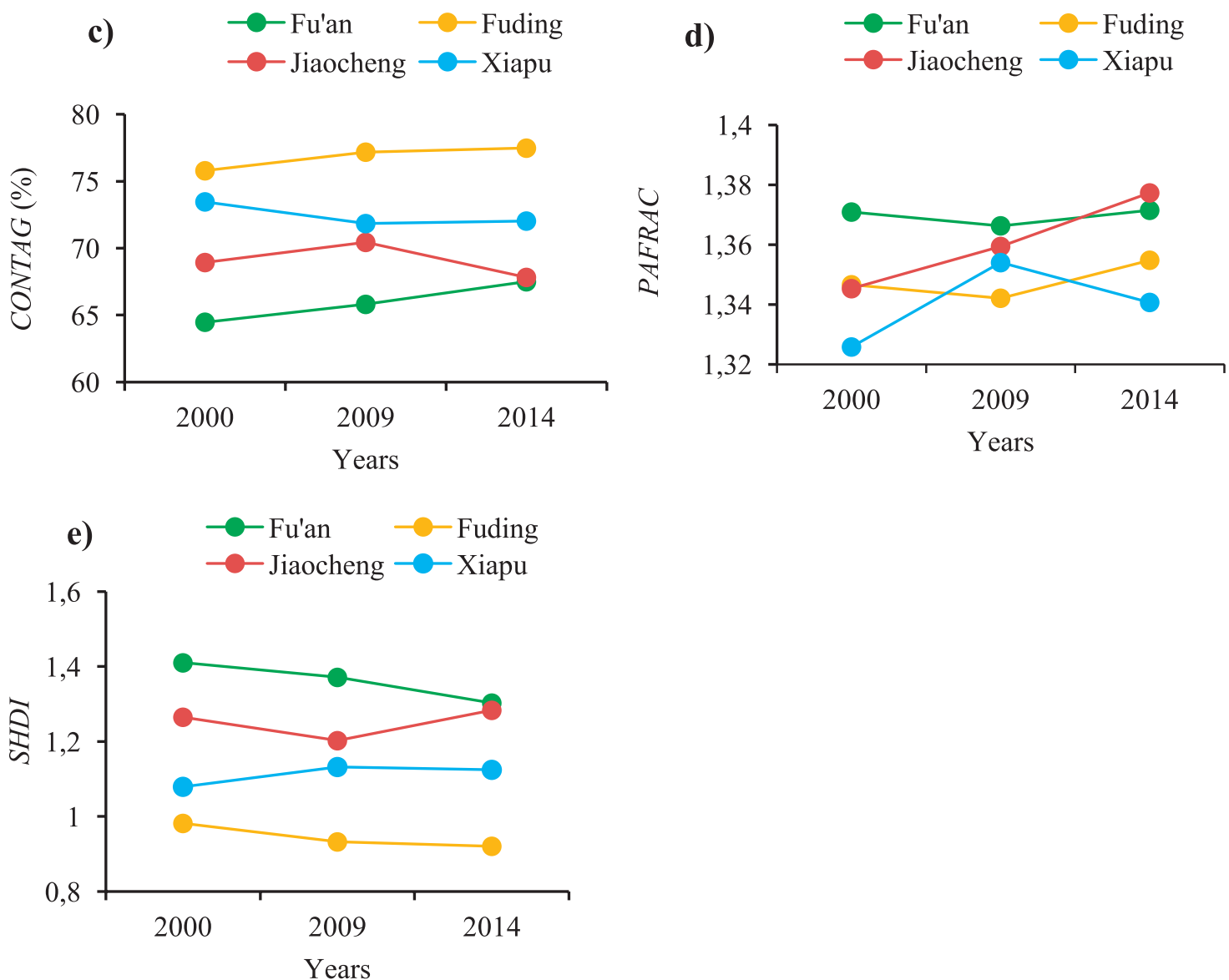

Fig. 2. Changes in the landscape indices for cities within the Ningde coastal zone.

patch types. Fig. 3 shows that dry land, paddy fields, forest, and grassland were the main landscape types. The area of paddy fields and dry land had gradually decreased from $25.41 \%$ and $36.83 \%$ in 2000 to $16.95 \%$ and $29.93 \%$ in 2014 , respectively, signifying an $8.46 \%$ and $6.90 \%$ decrease over the 14 years. The area of forest and grassland has gradually increased from $26.72 \%$ in 2000 to $43.47 \%$ in 2014 , with an increase of $16.75 \%$.

Fig. 4 shows that the number of patches in dry land, paddy fields, and rivers was significantly higher than that of other landscape types; this means that these landscape types were more fragmented. However, the average $N P$ in forests and grasslands with larger areas was only 1623 , indicating a more concentrated distribution. For construction land, the number of patches had reduced from 1764 in 2000 to 710 in 2014, with a decrease of 1054 over the 14 years. Furthermore, the area of construction land had essentially remained the same, suggesting that the distribution of construction land was concentrated. In addition, there was low fragmentation of other landscape types due to the small number of patches and area.

Fig. 5 shows that the $I J I$ of dry land, paddy fields, forest, and grassland were lower than $65 \%$. This indicates that these landscape types had less contact with surrounding landscape types. However, the 

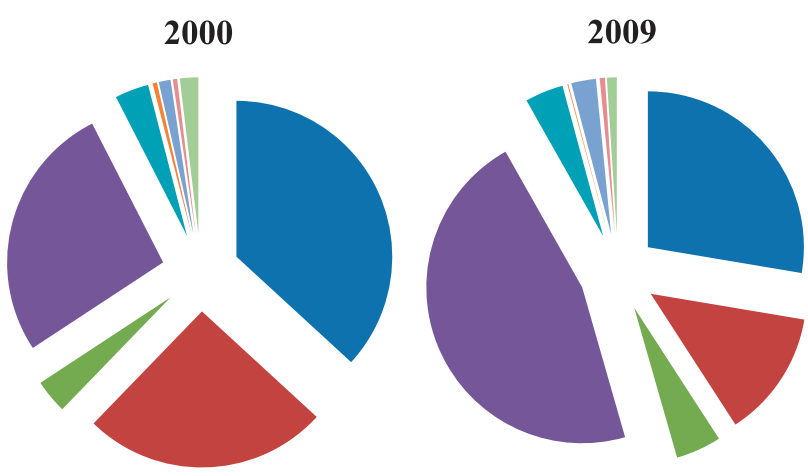

2014

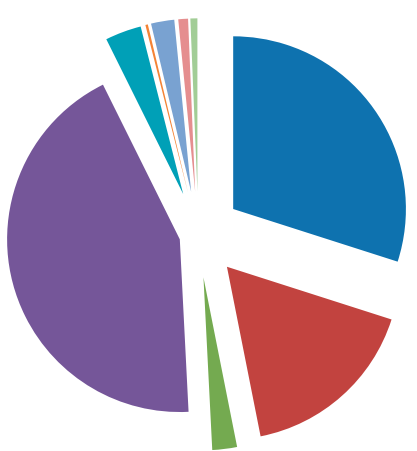

Dry land

- Paddy fields

- Rivers

- Forestland and grassland

- Construction land

- Lakes

Aquaculture

Reservoirs

Unused land

Fig. 3. Changes in the $P L A N D$ for the landscape types within the Ningde coastal zone (\%).

average $I J I$ of rivers, construction land, and unused land was $74.28 \%$, indicating that these landscape types were concentrated, particularly in lakes, aquaculture, and
2000
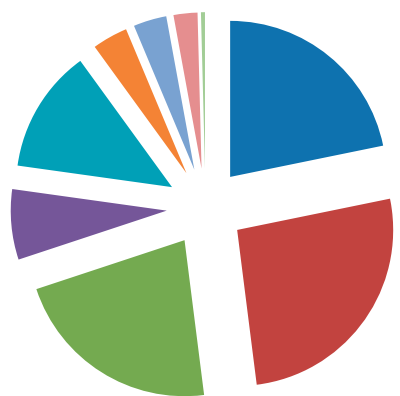

2014

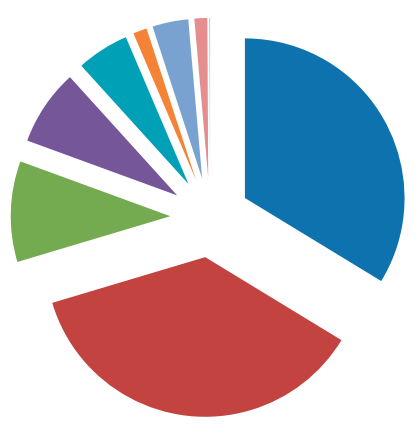

2009

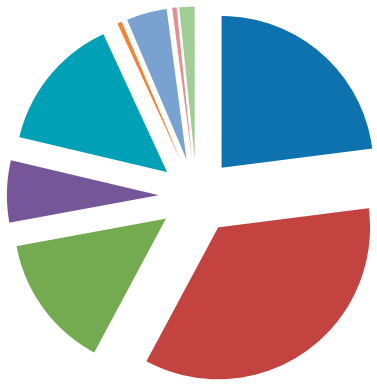

- Dry land

- Paddy fields

- Rivers

- Forestland and grassland

- Construction land

- Lakes

- Aquaculture

- Reservoirs

- Unused land
Fig. 4. Changes in the $N P$ for the landscape types within the Ningde coastal zone.

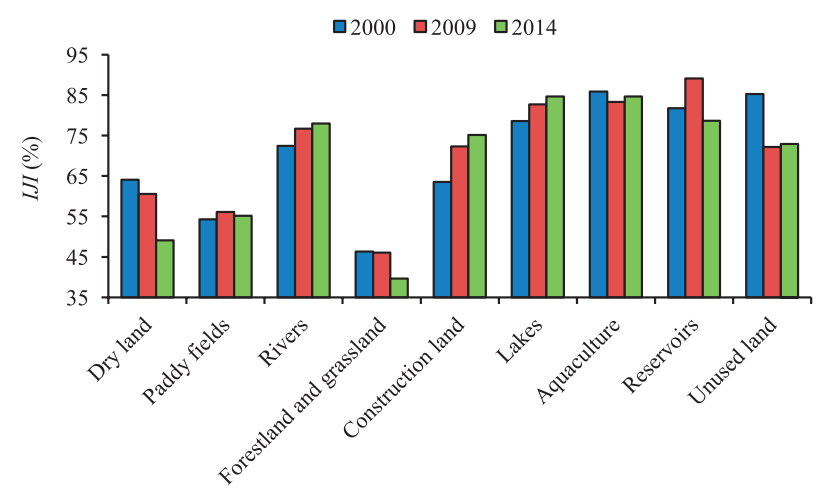

Fig. 5. IJI of landscape types within the Ningde coastal zone in 2000. 2009, and 2014.

reservoirs. Their average $I J I$ was above $80 \%$, and the $I J I$ of rivers, construction land, and lakes had shown an annual increase. This suggests that they were in closer contact with the surrounding landscape types over time. In contrast, the $I J I$ for dry land, forest, and grassland had decreased each year, suggesting that they had gradually become isolated in the landscape over time.

Fig. 6 shows that the average PAFRAC for dry land, paddy fields, rivers, forest, grassland, and construction land were 1.362 , indicating a more complex shape. In contrast, the average PAFRAC of lakes, aquaculture, reservoirs, and unused land was 1.258 , representing a more regular shape. From 2000 to 2014, the PAFRAC of dry land, lakes, and unused land have been increasing, particularly in forests and grasslands. This indicates that their shapes tend to become more complex. The PAFRAC of paddy fields had been declining over time, signifying a tendency toward a regular shape.

\section{Socio-Economic Driving Factors in the Coastal Zone}

Following PCA, two principal components were obtained as their initial feature value was greater than 1 and the accumulation value was greater than $85 \%$ (Table 3). The accumulation value of the initial two principal components was $85.97 \%$; this means that these two principal components represented $85.97 \%$ of

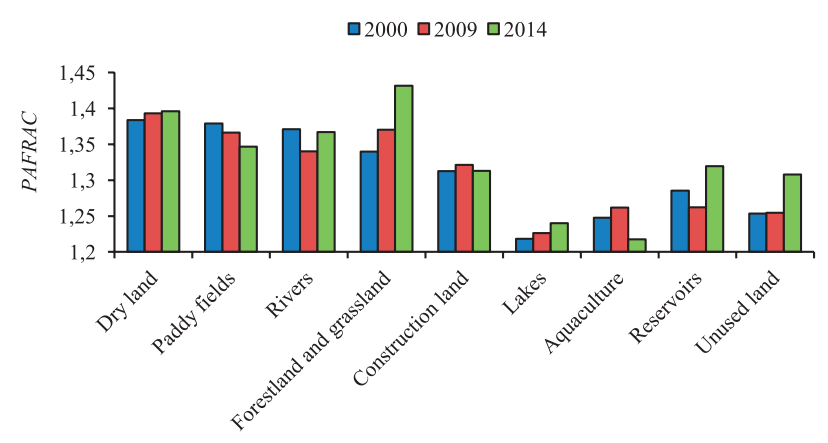

Fig. 6. PAFRAC of landscape types within the Ningde coastal zone in 2000. 2009, and 2014. 
Table 3. Initial feature values of the principal components.

\begin{tabular}{|c|c|c|c|}
\hline $\begin{array}{c}\text { Principal } \\
\text { components }\end{array}$ & Total & $\begin{array}{c}\text { Variance } \\
(\%)\end{array}$ & $\begin{array}{c}\text { Accumulation } \\
(\%)\end{array}$ \\
\hline 1 & 13.75 & 76.38 & 76.38 \\
\hline 2 & 1.73 & 9.59 & 85.97 \\
\hline
\end{tabular}

the total information. Therefore, these two principal components represented the 18 drivers of landscape change.

The load matrix of these drivers (Table 4) was rotated using the maximum variance to more efficiently explain the principal component; the results are shown in Table 5. These results show that the correlation coefficient between the first principal component and demographic factors excluding population density exceeded 0.900 . This indicates that population was the main driver of landscape change in the Ningde coastal zone. The correlation coefficient between the first principal component and the primary industry, tertiary industry, gross agricultural output, and average annual salary of all employees exceeded 0.800 , suggesting that economy and consumption produced landscape change in the coastal zone. The correlation coefficient between the second principal component and total investment in fixed assets was 0.769 , indicating that technology was also one of the drivers influencing landscape change.

The population of the Ningde coastal zone increased from 2.08 million in 2000 to 2.30 million in 2014 with an increase of 0.22 million in 14 years. This large population increase has triggered a daily increase in the demand for agricultural products. However, the implementation of policies to return farmland to forests has led to a significant reduction in the area of cultivated land. Therefore, the only solution is to improve the productivity of the cultivated land by exploring agricultural technology. There have been improvements to land quality and food yield, suggesting that technology is one of the influencing factors affecting landscape changes in the Ningde coastal zone.

The loading matrix data (Table 4) were input into the Data Editor window of SPSS software, and the eigenvector was calculated using data conversion. The expression of two principal components was obtained using the eigenvector and standardized data to determine the changes to the impact of these drivers on the Ningde coastal zone landscape over time (Equations 14 and 15):

Table 4. Loading matrix of the selected socio-economic drivers.

\begin{tabular}{|c|c|c|c|}
\hline Code & Name of driver & Component 1 & Component 2 \\
\hline $\mathrm{ZX}_{1}$ & Household registration & 0.891 & -0.421 \\
\hline $\mathrm{ZX}_{2}$ & Total population & 0.858 & -0.460 \\
\hline $\mathrm{ZX}_{3}$ & Urban population & 0.791 & -0.520 \\
\hline $\mathrm{ZX}_{4}$ & Population density & 0.312 & 0.459 \\
\hline $\mathrm{ZX}_{5}$ & Rural population & 0.937 & -0.298 \\
\hline $\mathrm{ZX}_{6}$ & Gross domestic product & 0.985 & 0.145 \\
\hline $\mathrm{ZX}_{7}$ & Primary industry & 0.941 & -0.178 \\
\hline $\mathrm{ZX}_{8}$ & Secondary industry & 0.927 & 0.029 \\
\hline $\mathrm{ZX}_{9}$ & Tertiary Industry & 0.946 & -0.096 \\
\hline $\mathrm{ZX}_{10}$ & Industrial output & 0.914 & 0.327 \\
\hline $\mathrm{ZX}_{11}$ & Gross agricultural output value & 0.974 & 0.015 \\
\hline $\mathrm{ZX}_{12}$ & Local fiscal revenue & 0.916 & 0.309 \\
\hline $\mathrm{ZX}_{13}$ & Local fiscal expenditure & 0.954 & 0.240 \\
\hline $\mathrm{ZX}_{14}$ & Total investment in fixed assets & 0.871 & 0.356 \\
\hline $\mathrm{ZX}_{15}$ & $\begin{array}{l}\text { Total retail sales of social consumer } \\
\text { goods }\end{array}$ & 0.983 & 0.075 \\
\hline $\mathrm{ZX}_{16}$ & $\begin{array}{l}\text { Urban and rural residents' savings } \\
\text { balance }\end{array}$ & 0.964 & 0.198 \\
\hline $\mathrm{ZX}_{17}$ & $\begin{array}{c}\text { Average annual salary of all em- } \\
\text { ployees }\end{array}$ & 0.867 & -0.143 \\
\hline $\mathrm{ZX}_{18}$ & Natural population growth rate & 0.258 & 0.502 \\
\hline
\end{tabular}


Table 5. Rotated loading matrix of selected socio-economic drivers.

\begin{tabular}{|c|c|c|c|c|}
\hline Code & Name of driver & Component 1 & Component 2 & Type of driver \\
\hline $\mathrm{ZX}_{1}$ & Household registration & 0.977 & 0.125 & \multirow{5}{*}{ Population } \\
\hline $\mathrm{ZX}_{2}$ & Total population & 0.971 & 0.074 & \\
\hline $\mathrm{ZX}_{3}$ & Urban population & 0.947 & -0.013 & \\
\hline $\mathrm{ZX}_{4}$ & Population density & 0.015 & 0.555 & \\
\hline $\mathrm{ZX}_{5}$ & Rural population & 0.950 & 0.253 & \\
\hline $\mathrm{ZX}_{6}$ & Gross domestic product & 0.752 & 0.653 & \multirow{8}{*}{ Economy } \\
\hline $\mathrm{ZX}_{7}$ & Primary industry & 0.889 & 0.357 & \\
\hline $\mathrm{ZX}_{8}$ & Secondary industry & 0.766 & 0.524 & \\
\hline $\mathrm{ZX}_{9}$ & Tertiary Industry & 0.849 & 0.429 & \\
\hline $\mathrm{ZX}_{10}$ & Industrial output & 0.594 & 0.767 & \\
\hline $\mathrm{ZX}_{11}$ & Gross agricultural output value & 0.813 & 0.537 & \\
\hline $\mathrm{ZX}_{12}$ & Local fiscal revenue & 0.606 & 0.754 & \\
\hline $\mathrm{ZX}_{13}$ & Local fiscal expenditure & 0.675 & 0.716 & \\
\hline $\mathrm{ZX}_{14}$ & Total investment in fixed assets & 0.542 & 0.769 & Technology \\
\hline $\mathrm{ZX}_{15}$ & Total retail sales of social consumer goods & 0.788 & 0.593 & \multirow{3}{*}{ Consumption } \\
\hline $\mathrm{ZX}_{16}$ & Urban and rural residents' savings balance & 0.705 & 0.686 & \\
\hline $\mathrm{ZX}_{17}$ & Average annual salary of all employees & 0.808 & 0.346 & \\
\hline $\mathrm{ZX}_{18}$ & Natural population growth rate & -0.053 & 0.562 & Social awareness \\
\hline
\end{tabular}

$$
\begin{gathered}
\mathrm{F}_{1}=0.2403 \mathrm{ZX}+0.2314 \mathrm{ZX}+\mathrm{V} 0.2133 \mathrm{ZX} \\
0.0841 \mathrm{ZX}_{4}+0.2527 \mathrm{ZX}_{5}+0.2657 \mathrm{ZX}_{6} \\
+0.2538 \mathrm{ZX}_{7}+0.25 \mathrm{ZX}_{8}+0.2551 \mathrm{ZX}_{9}+0.2465 \mathrm{ZX} \\
+0.2627 \mathrm{ZX}_{11}+0.2470 \mathrm{ZX} \\
+0.2349 \mathrm{ZX} \mathrm{X}_{14}+0.2651 \mathrm{ZX}_{15}+0.2600 \mathrm{ZX} \\
+0.2338 \mathrm{ZX} \mathrm{X}_{17}+0.0696 \mathrm{ZX} \\
+0
\end{gathered}
$$

$$
\begin{gathered}
\mathrm{F}=0.178 \mathrm{ZX}_{1}+0.167 \mathrm{ZX}_{2}+0.145 \mathrm{ZX}_{3}+0.114 \mathrm{ZX} \\
+0.199 \mathrm{ZX}_{5}+0.248 \mathrm{ZX}_{6}+0.210 \mathrm{ZX}_{7}+0.225 \mathrm{ZX}_{8} \\
+0.219 \mathrm{ZX}_{9}+0.247 \mathrm{X}_{10}+0.235 \mathrm{ZX}_{11}+0.246 \mathrm{ZX}_{12} \\
+0.249 \mathrm{ZX}_{13}+0.239 \mathrm{ZX}_{14}+0.242 \mathrm{ZX}_{15}+0.248 \mathrm{ZX}_{16} \\
+0.196 \mathrm{ZX}_{17}+0.104 Z \mathrm{X}_{18}
\end{gathered}
$$

The covariance matrix of the principal component scores was obtained using PCA (Table 6). This was a unit matrix, indicating that the extracted principal components $\mathrm{F}_{1}$ had no relationship with $\mathrm{F}_{2}$; therefore, the integrated model, $\mathrm{F}$, was achieved (Equation 16). F was determined using Formulas 14, 15, and 16:

$$
F=\frac{\lambda_{1}}{\lambda_{1}+\lambda_{2}} F_{1}+\frac{\lambda_{2}}{\lambda_{1}+\lambda_{2}} F_{2}
$$

$$
\begin{gathered}
\mathrm{F}=0.178 Z \mathrm{X}_{1}+0.167 \mathrm{ZX}+0.145 \mathrm{ZX}+0.114 \mathrm{ZX} \\
+0.199 \mathrm{ZX}_{5}+0.248 \mathrm{ZX}_{6}+0.210 \mathrm{ZX} \mathrm{X}_{7}+0.225 \mathrm{ZX}_{8}
\end{gathered}
$$

$+0.219 Z X_{9}+0.247 X_{10}+0.235 Z X_{11}+0.246 Z X_{12}$ $+0.249 \mathrm{ZX}_{13}+0.239 \mathrm{ZX}_{14}+0.242 \mathrm{ZX}_{15}+0.248 \mathrm{ZX}_{16}$ $+0.196 Z_{17}^{14}+0.104 Z X_{18}^{15}$

From Fig. 7, the total score of the socio-economic drivers influencing the Ningde coastal zone continued to rise from 2000 to 2014 . The value increased from -0.186 in 2000 to 3.808 in 2009 and continued to rise to 9.719 in 2014. This indicates that the impact of these drivers on the Ningde coastal zone landscape has consistently increased. Fig. 8 also shows that the scores of the socioeconomic drivers of these cities also continued to rise. However, most of these scores were negative during the study period. Only the values for Fuding and Fu'an in 2014 were positive, being 0.492 and 0.636 , respectively. This showed that the influence of the socio-economic drivers on landscape changes in Xiapu and Jiaocheng was weak. Fu'an and Xiapu had the highest and lowest average scores, with values of -0.955 and -1.985 , respectively. This indicates that landscape changes in

Table 6. Covariance matrix of principal component scores.

\begin{tabular}{|c|c|c|}
\hline Component & 1 & 2 \\
\hline 1 & 1.000 & .000 \\
\hline 2 & .000 & 1.000 \\
\hline
\end{tabular}




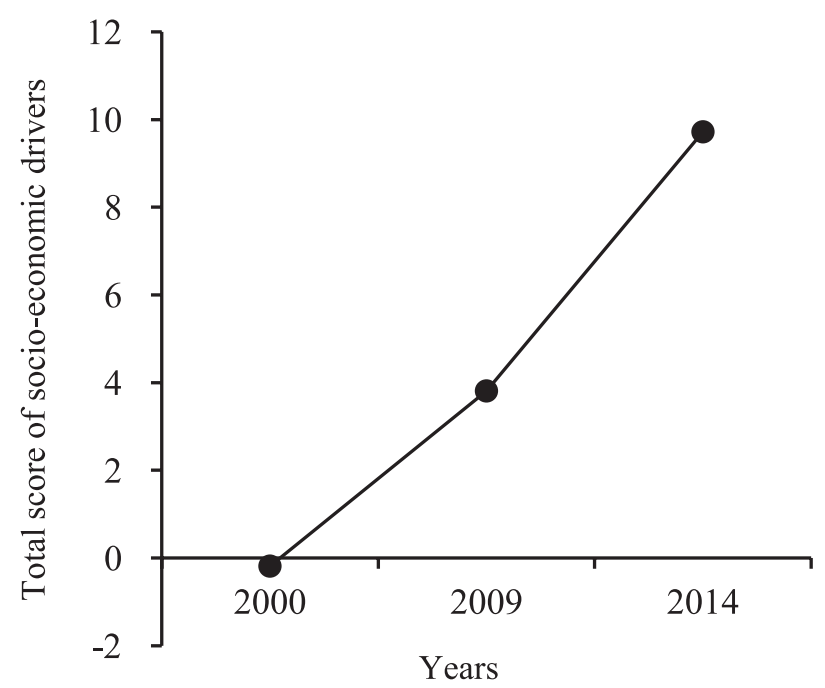

Fig. 7. Total score of socio-economic drivers influencing landscape changes in the Ningde coastal zone.

Fu'an and Xiapu were the most and least affected by socio-economic drivers.

In addition to these influential drivers, policy was also a factor that affected landscape changes in the Ningde coastal zone. As policy could not be quantified in this study, only a qualitative assessment of the impact of policy was possible. Land policies and regulations have had a significant impact on landscape changes in the coastal zone. For example, the Chinese central government issued a number of opinions on pilot studies where farmland (dry land and paddy fields) were rehabilitated back to forest and grassland in 2002 . Therefore, over the 14 years of the study, the area of forestland and grassland has increased significantly to $1047.240 \mathrm{~km}^{2}$, whereas the area of dry land and paddy fields has significantly reduced to $959.450 \mathrm{~km}^{2}$ in total. These impacts emphasize that policy was also a key driver in influencing landscape changes in the Ningde coastal zone.

This study analyzed remote sensing data on the Ningde coastal zone, taken over 14 years, using GIS, RS, and Fragstats software. It used the landscape pattern index and principal component analysis methods to study the dynamic changes in the landscape pattern of the Ningde coastal zone from 2000 to 2014 and mechanisms driving that change. This research has a certain theoretical value and great significance in terms of providing strong practical guidance to promote the coordinated and sustainable development of the economy, society, and ecological environment of the Ningde coastal zone.

This study found that the driving factors affecting the evolution of the landscape pattern of the Ningde coastal zone included the population level, technology, and consumption, as well as economic and policy concerns. Parcerisas et al. [17] stated that urban expansion and agricultural abandonment were the main reasons
Fuding
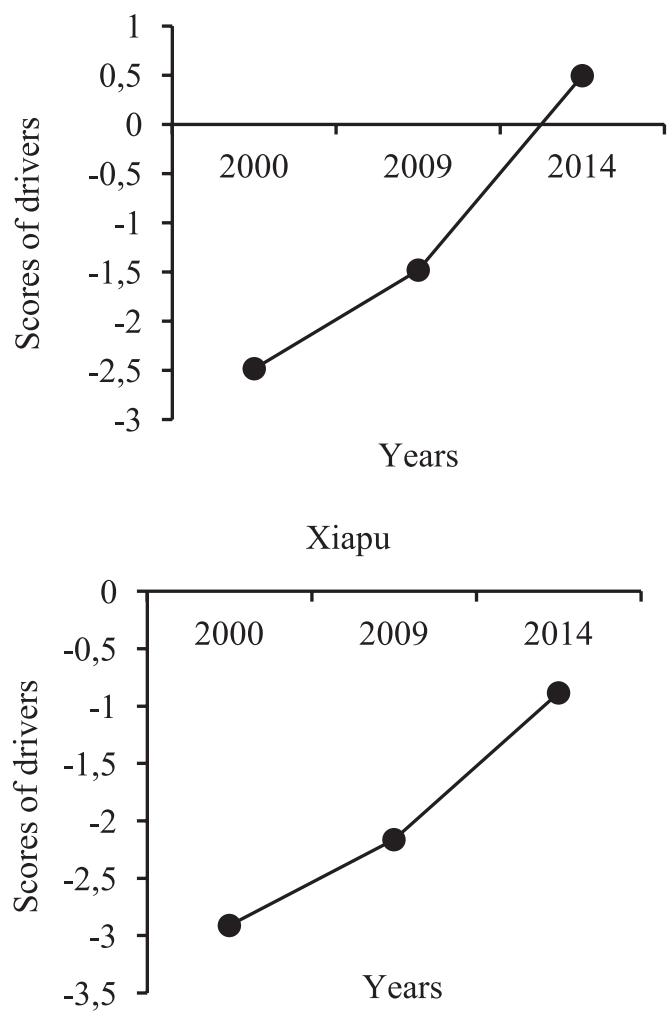

Fu'an
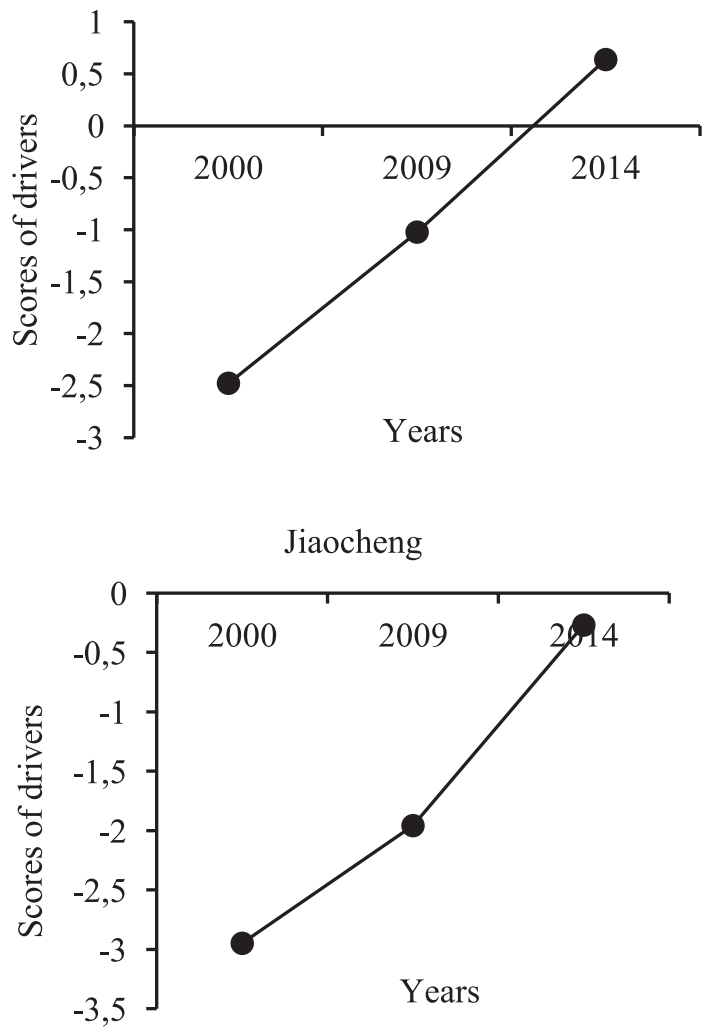

Fig. 8. Scores of drivers influencing the landscape changes on the cities within the Ningde coastal zone. 
for the degradation of the landscape of the Spanish Mediterranean coast. Petrisor et al. [2] found that urban expansion and the development of tourism were the main reasons for changes in the landscape in the coastal areas of Vietnam. Urbanization, the development of agricultural, and population growth and migration have led to the degradation of the landscape in the coastal areas of Algeria. Urbanization or urban expansion, the development of agriculture, the development of tourism, and population growth and migration in the above studies correspond, respectively, to the economy, technology, consumption, and population factors in this study. Therefore, this study produced results similar to those of the above studies. Although the factors influencing changes in the landscape pattern in different coastal areas were different, they generally included population, technology, economy, and consumption factors.

However, this study still has some shortcomings, although it has in general enriched the body of case studies on changes in the evolution of coastal landscape patterns and the mechanisms driving these and effectively ranked the factors driving these changes in terms of their influence.

(1) This study paid close attention to dynamic changes in the landscape pattern of terrestrial areas but did not consider the interaction between the land and the sea. It is well known that ecological processes along coastal landscapes differ from those of other terrestrial landscapes because the former involves many factors related to the aquatic environment. Therefore, future research could examine how to integrate marine environmental factors into research on coastal terrestrial landscape ecology and how to couple the mechanisms that cause changes in coastal terrestrial landscape patterns and marine processes.

(2) Research on dynamic changes in coastal landscape patterns should be combined with that on coastal ecosystem service functions. Assessing the service functions of coastal ecosystems and predicting the trends in their future development will suggest a way to manage coastal ecosystems such that they continue to services useful to humans.

\section{Conclusions}

During the study period, the total area of the Ningde coastal zone has continued to increase, whereas the patch types remained unchanged and patch shapes increased in complexity. The number and density of patches decreased, and the influence of dominant patches had gradually weakened. The heterogeneity and fragmentation of patches had decreased, whereas the natural connectivity of the patches had increased, and patches were tending toward increased aggregation.

$\mathrm{NP}, \mathrm{PD}$, and fragmentation of the landscape in Xiapu were on the rise. The patch shape and patch composition tended to be more complex. The number and density of patches and landscape fragmentation in Fu'an showed a downward trend. Patch shape and composition were the most complicated. In Fuding, NP and PD showed a downward trend, whereas landscape fragmentation showed an upward trend. The shape of patches tended to be complex, although patch composition was the simplest. In Jiaocheng, NP, PD, and fragmentation increased, and the shape and composition of the patches was increasing in complexity.

The landscape was dominated by dry land, paddy fields, and forest and grassland with increasingly complex shapes. These landscape types were isolated from the landscape; the dry land and paddy fields were more fragmented, whereas the forest land and grassland had become increasingly concentrated. Despite the lower area of construction land and rivers, these landscape types were more scattered and were in close contact with lakes, aquaculture, reservoirs, and unused land.

Population, economy, consumption, and technology were the drivers influencing landscape changes in the Ningde coastal zone. The influence of these drivers on the landscape changes followed the order of population $>$ economy $>$ consumption $>$ technology; the implementation of recent policy was also a driver that influenced the landscape changes in the Ningde coastal zone. The socio-economic drivers influencing landscape changes in the Ningde coastal zone had continued to increase during the study period.

\section{Acknowledgements}

This work was supported by the Education Department of Hunan Province (No.19C1670), the Specialized Research Fund for the Doctoral Program of Shaoyang University (No. 17ZX03).

\section{Conflict of Interest}

No conflict of interest exits in the submission of this manuscript, and manuscript is approved by all authors for publication.

\section{References}

1. ARAYA Y.H., CABRAL P. Analysis and modeling of urban land cover change in Setúbal and Sesimbra, Portugal. Remote Sens-Basel, 2 (6), 1549, 2010.

2. PETRISOR A.I., HAMMA W., NGUYEN H.D., RANDAZZO G., MUZIRAFUTI A., STAN M.I., TRAN V.T., ASTEFANOAIEI R., BUI Q.T., VINTILA D.F., TRUONG Q.H., LIXANDROIU C., TENEA D.D., SIRODOEV I., IANOS I. Degradation of the coastlines under the pressure of urbanization: evidence from Europe, Asia and Africa. Land, 9 (8), 275, 2020.

3. WANG X.R., LING H.R., HUANG J., FAN Z.Q., WANG Y., YONG Y. Global Climate Change and Strategy 
of Eco-Zoning for Climate Vulnerability of Estuary City - A case study of Shanghai. Shanghai Urban Planning Review, (6), 1549, 2012.

4. SUO A.N., GUAN D.M., SUN Y.G., LIN Y., ZHANG M.H. Advances in coastal landscape ecology and its role in the construction of marine ecological civilization. Acta Ecologica Sinica, 36 (11), 3167, 2016.

5. HOU X.Y., LIU J., SONG Y., LI X.W. Environmentalecological effect of development and utilization of China's coastline and policy recommendations. Bulletin of Chinese Academy of Sciences, 31 (10), 1143, 2016.

6. NGUYEN H.D., HAMMA W, STAN M.-I., TRAN V.T., ASTEFANOAIEI R., BUI Q.T., VINTILA D.F., PHAM Q.T., LIXANDROIU C., TRUONG Q.H., TENEA D.D., IANOS I. Impacts of urbanization and tourism on the erosion and accretion of European, Asian and African coastal areas and possible solutions. Urban Arhit Constr, 11 (2), 123, 2020.

7. MALAVASI M, VOJTĚCH BARTÁK, CARRANZA M.L., íMOVÁ P., ACOSTA A.T.R. Landscape pattern and plant biodiversity in Mediterranean coastal dune ecosystems: Do habitat loss and fragmentation really matter? J Biogeogr, 45 (6), 1367, 2018.

8. MCINTYRE J.K., LUNDIN J.I., CAMERON J.R., CHOW M.I., DAVIS J.W, INCARDONA J.P., SCHOLZ N.L. Interspecies variation in the susceptibility of adult Pacific salmon to toxic urban stormwater runoff. Environ Pollut, 238, 196, 2018.

9. ZHAI T., WANG J., FANG Y., QIN Y., HUANG L.Y, CHEN Y. Assessing ecological risks caused by human activities in rapid urbanization coastal areas: Towards an integrated approach to determining key areas of terrestrialoceanic ecosystems preservation and restoration. Sci Total Environ, 708, 135153, 2020.

10. GOLD A.C., THOMPSON S.P., MAGEL C.L., PIEHLER M.F. Urbanization alters coastal plain stream carbon export and dissolved oxygen dynamics. Sci Total Environ, 747, 141132, 2020.

11. YI L., CHEN J.S., JIN Z.F., QUAN Y.M., HAN P.P., GUAN S.J., JIANG X.L. Impacts of human activities on coastal ecological environment during the rapid urbanization process in Shenzhen, China. Ocean Coastal Manage, 154, 121, 2018.

12. XIA C.Q., WU Y.F. Land use types and landscape dynamics and analysis in the coastal zone of Yancheng. Journal of Southwest Forestry University, 41 (1), 1, 2021.

13. WAN Y.L., JIN R., TANG J.B., JIN H.M. Spatial heterogeneity of urban expansion structure based on spatial clustering method in Dongguan City. Econ Geogr, 39 (3), 84, 2019.

14. BRAGHINA C., PEPTENATU D., DRAGHICI C., PINTILII R.D., SCHVAB A. Territorial management within the systems affected by Mining. Case study the south-western development region in Romania. Iran $\mathrm{J}$ Environ Healt, 8 (4), 315, 2011.

15. ESTEVE P., JAEN M., BANOS-GONZALEZ I. Changes in the level of relationship between invertebrates and society of pre-service primary school teachers, after an educational intervention. J Biol Educ, (4), 1, 2019.

16. ZHOU Y., NING L., BAI X. Spatial and temporal changes of human disturbances and their effects on landscape patterns in the Jiangsu coastal zone, China. Ecol Indic, 93, 111,2018

17. PARCERISAS L., MARULL J., PINO J., TELLO E., COLL F., BASNOU C. Land use changes, landscape ecology and their socioeconomic driving forces in the Spanish mediterranean coast (El Maresme County, 18502005). Environ Sci Policy, 23,120, 2012.

18. RIVIS R., KONT A., RATAS U., PALGINOMM V., ANTSO K., TONISSON H. Trends in the development of Estonian coastal land cover and landscapes caused by natural changes and human impact. J Coast Conserv, 20 (3), 199, 2016

19. OU W.X., YANG G.S., LI H.P., YU X.X. Spatio-temporal variation and driving forces of landscape patterns in the coastal zone of Yancheng, Jiangsu. Scientia Geographica Sinica, 24 (5), 610, 2004.

20. DING Z. Remote sensing of land reclamations and its impact on wetland landscapes along the Bohai Gulf, China. University of Chinese Academy of Sciences, Changchun, 2014.

21. XU W.Y., XIE X.P., CHEN Z.C., BAI M.W., YE H. The analysis of dynamic evolution on coastal landscape patterns based on the satellite images in Rizhao City, Shandong Province. Journal of Qufu Normal University, 43 (3), 93, 2017.

22. TURNER B.L.I., SKOLE D.L., SANDERSON S., FISCHER G., FRESCO L., LEEMANS R. Land cover change science/research plan. IGBP Report 35, HDP Report 7. Stockholm and Geneva, 1995.

23. EHRICH P.R., DAILY G.C. Population extinction and saving biodiversity. Ambio, 22 (2-3), 64, 1993.

24. ZHAO L.L., YOU W.B., HU H.Q., HONG W., LIAO X.J., XIAO S.H., WANG R., CAI J.B., FAN X.C., TAN Y. Spatial distribution of heavy metals $(\mathrm{Cu}, \mathrm{Pb}, \mathrm{Zn}$, and $\mathrm{Cd}$ ) in sediments of a coastal wetlands in eastern Fujian, China. J Foretsry Res, 26 (3), 703, 2015.

25. SU S.C. Coastal wetland landscape pattern dynamics and its vulnerability assessment feature in Eastern of Fujian Province. Fujian Agriculture and Forestry University, Fuzhou, 2013.

26. HE D.J., LI L., YOU W.B., WANG R., CAI J.B., LIAO X.J. Landscape pattern changes of coastal wetlands and its simulation in eastern Fujian Province. Journal of Fujian College of Forestry, 33 (2), 97, 2013.

27. HOU D.L., HE D.J., HONG W., YOU W.B., WU L.Y., JI Z.R., XIAO S.H. Influence of invasive Spartina alterniflora on soil ecosystem in coastal wetland. Wetland Science and Management 11(4): 67, 2015.

28. ZHENG S.Y. Assessment of seawater quality in Large Yellow Croaker aquaculture area in Sanduao using Set Pair Analysis. Chinese Journal of Fisheries, 28 (2), 36, 2015.

29. NINGDE STATISTICS BUREAU(NSB). Ningde statistical yearbook. China Statistics Press, Beijing, 2019.

30. NINGDE STATISTICS BUREAU(NSB). Ningde statistical yearbook. China Statistics Press, Beijing, 2000.

31. NINGDE STATISTICS BUREAU(NSB). Ningde statistical yearbook. China Statistics Press, Beijing, 2009.

32. NINGDE STATISTICS BUREAU(NSB). Ningde statistical yearbook. China Statistics Press, Beijing, 2014.

33. GRAFIUS D.R., CORSTANJE R., HARRIS J.A. Linking ecosystem services, urban form and green space configuration using multivariate landscape metric analysis. Landscape Ecol, 33 (4), 557, 2018.

34. FAN X.C., LIU J.B., CHEN J.Z., ZHAO L.L., HONG W., HONG T., LIN H. Effects of landscape changes on ecosystem services: a case study in Nanping City, Northern Fujian Province, China. Fresen Environ Bull, 27 (5A), 3561, 2018.

35. RINGNÉ M. What is principal component analysis? Nat Biotechnol, 26 (3), 303, 2008. 
36. YANG D.C., GAO C., LI L.Y., VAN EETVELDE V. Multiscaled identification of landscape character types and areas in Lushan National Park and its fringes, China. Landscape Urban Plan, 201, 103844, 2020.

37. LEE D.C., POWELL V.J., LINDSELL J.A. Understanding landscape and plot-scale habitat utilisation by Malayan sun bear (Helarctos malayanus) in degraded lowland forest. Acta Oecol, 96, 1, 2019.

38. PETANIDOU T., KIZOS T., SOULAKELLIS N. Socioeconomic dimensions of changes in the agricultural landscape of the Mediterranean Basin: a case study of the abandonment of cultivation terraces on Nisyros Island, Greece. Environ Manage, 41 (2), 250, 2008.

39. HERNÁNDEZ A., MIRANDA M.D., ARELLANO E.C., DOBBTS C. Landscape trajectories and their effect on fragmentation for a Mediterranean semi-arid ecosystem in Central Chile. J Arid Environ, 127, 74, 2016.

40. HANDAVU F., CHIRWA P.W.C., SYAMPUNGANI S. Socio-economic factors influencing land-use and landcover changes in the miombo woodlands of the Copperbelt province in Zambia. Forest Policy and Econ, 100, 75, 2019. 